\title{
A Difusão do Conhecimento sobre Organizações e Gestão no Brasil: Seis Propostas de Ensino para o Decênio 2000/2010
}

\author{
Tânia Maria Diederichs Fischer
}

\section{RESUMO}

O título acima evoca as seis propostas para o milênio referidas à criação literária. Um dos melhores trabalhos do final do século XX e último livro de Calvino (1991), presta-se a muitas leituras e aplicações. Leveza, agilidade, visibilidade, multiplicidade, precisão e consistência são princípios que interferem em conteúdos e formas literárias aqui utilizadas para tratar da reflexividade do ensino de organizações e gestão. O que se ensina no Brasil, de que forma o conhecimento é selecionado e reorganizado como matéria de ensino, segundo a natureza deste conhecimento nos diversos níveis em que o ensino é ministrado e ocorrem aprendizagens são o foco principal deste trabalho, que se refere a resultados de pesquisa realizada com a comunidade de professores dos programas de pós-graduação. Como pressuposto, o gap entre a revolução das formas organizacionais da contemporaneidade, as múltiplas variantes de poder e a rigidez dos desenhos curriculares têm a disciplina como unidade produtiva dos cursos. O investimento em novas formas organizativas de ensino coerentes com o conteúdo do que se pesquisa e com os avanços das teorias que moldam o campo multifacetado dos estudos organizacionais, é um desafio à comunidade de professores, hoje articulados pela ANPAD.

Palavras-chaves: ensino de organizações e gestão; epistemologia; interdisciplinariedade; novos desenhos curriculares; docência e gestão do conhecimento.

\begin{abstract}
The title above evocates six proposals to the millennium referred to the literary creation. One of the best works of the end of the $20^{\text {th }}$ century and last book of Calvino (1991) refers itself to many readings and applications. Lightness, fastness, visibility, multiplicity, precision and consistency are principles that interferes in literary contents and forms here utilized to talk about reflectivity of the teaching of organizations and management. What is taught in Brazil, the way how the knowledge is selected and reorganized like subject of teaching, in conformity with the nature of this knowledge in many levels in which the teaching is ministered and occurs learning, are the main focus of this work; that refers to results of research realized with the community of teachers of postgraduation programs. As assumed, the gap in the revolution of the organizational forms of today, multiple versions of power and the rigidity of the curriculums draws have the discipline as productive unity of the courses. The investments in new organizational forms of teaching coherent with the contents that are researched and with the advances of theories that mould the varied space of the organizational studies is a challenge to the community of teachers, nowadays articulated by the ANPAD.
\end{abstract}

Key words: teaching of organization and management; epistemology; interdisciplinarity; new curricula forms; management of knowledge and learning. 


\section{A Trajetória Brasileira: Pretérito Imperfeito e Presente Composto}

O ensino formal de administração completa 50 anos, quando o país chega ao quinto século. Não ignoramos que a prática administrativa e mesmo as decisões estratégicas antecederam o país, que não foi descoberto por acaso. Desde a Colônia, as experiências de gestão se sucedem e o país vai sendo construído por elas e apesar delas.

Os ensaios do Visconde do Uruguai sobre a descentralização no Império, os textos de Machado de Assis refletindo a vida na burocracia pública, que é parte da sociedade de então, e a formidável saga do Barão de Mauá são apenas três exemplos do que se pensava e se vivia em organizações que não eram tão simples antes do agitado século XX, quando se institucionaliza o ensino de Administração pelas escolas que foram criadas nos anos 50 e 60, proliferando como em nenhuma outra área.

Vamos nos referir a dois momentos de institucionalização dando um corte no tempo: a implantação e o momento atual. Os anos 40 e 50 são decisivos para a inserção brasileira no cenário internacional. O Estado administrativo montado por Getúlio Vargas é o ponto de partida para a cooperação técnica com os Estados Unidos e as políticas de internacionalização da eficiência americana após a Segunda Guerra Mundial foram determinantes neste sentido.

O ensino de administração seguiu uma trajetória no Brasil muito semelhante a dos demais países terceiromundistas. Convênios de cooperação técnica foram estabelecidos entre os Estados Unidos e diversos países latino-americanos, africanos e asiáticos para a implantação de escolas de administração pública e de empresas, que tiveram o papel de pólos de irradiação (Fischer, 1984).

Em 9 de março de 1959, foi assinado um convênio muito importante para a área de administração, de conformidade com o Acordo sobre Serviços Técnicos Especiais, entre o Brasil e os Estados Unidos, firmado em 1953, designado por PBA-1. O projeto daí decorrente foi designado como Programa de Ensino de administração Pública e de Empresas, criando escolas de administração na Fundação Getúlio Vargas (São Paulo, sendo reforçada a escola já existente no Rio de Janeiro), na Universidade Federal do Rio Grande do Sul (UFRGS) e na Universidade Federal da Bahia (UFBA).

Para a consecução do pretendido desenvolvimento, o plano enfatiza a necessidade de formar professores com vistas a "prover suficiente número de técnicos competentes às repartições públicas e privadas". 
É curioso observar que o desenvolvimento foi a razão de ser dos esforços dos anos 50 e 60, em pleno apogeu do nacionalismo desenvolvimentista. No inicio deste milênio, as políticas de inserção na economia globalizada têm como estratégias compensatórias os programas disseminados por agências internacionais e nacionais de desenvolvimento local integrado e sustentável (Jouve, 1996; Veltz, 1996; Le Gallés, 1998; Moura, 1998; Balme, 1999). Que mudou nos cinqüenta anos de institucionalização do ensino de administração?

Primeiro, a quantidade de escolas. Difundido como produto de exportação, o ensino de administração rapidamente alastrou-se pelo país, chegando a 300 instituições nos anos 60, e que beira os 1.500 cursos no ano 2000, considerando apenas aqueles reconhecidos pelo Conselho Nacional de Educação.

A expansão maciça das ofertas e das demandas de ensino, presencial e à distância, não está restrita à graduação, mas se estende também à pós-graduação. O número de pedidos de reconhecimento de cursos de mestrado é quatro vezes maior do que há cinco anos (dados da Fundação CAPES); os cursos de especialização (muitos rotulados como MBAs) fazem parte da chamada terra de ninguém, tal o seu número e diversidade.

Segundo, a americanização dos currículos e programas deu lugar, progressivamente, ao reconhecimento de outras contribuições, como a produção européia (inglesa, francesa, italiana, escandinava); à articulação com escolas do mundo hispânico e latino-americano (UNAM, UNIANDES, IESA) e associações destas escolas (CLADEA, CLAD), bem como redes de pesquisadores, articulando brasileiros a grupos britânicos, franceses, canadenses, alemães, norte-americanos, espanhóis, portugueses e, mais raro, a grupos latino-americanos.

Terceiro, as críticas ao consenso ortodoxo e os efeitos do pensamento radical crítico tiveram efeito não desprezível nas fissuras do modelo disciplinar tradicional.

Afirma Aktouf (1998): "é mais freqüente que a formação seja centrada na lógica da reprodução, já que as escolas de gestão são ambientes conservadores e elitistas, que formam administradores e teóricos que tenderão a reproduzir os mesmos modelos e modos de pensar".

A introdução de disciplinas com conteúdo contestatório e alternativo ocorreu na década de 80 e convive com as disciplinas tradicionais.

Quarto, as contribuições do movimento pós-moderno, no qual não cabe tudo, mas tudo cabe, têm provocado uma saudável desconstrução/reconstrução. A tradução e adaptação do Handbook de Estudos Organizacionais (Clegg, Hard e Nord, 1996), liderada por Caldas e outros, possibilitou a reflexão de pesquisadores brasileiros sobre organizações brasileiras e o estado da arte no Brasil. 
O Grupo de Estudos Organizacionais (GEO) é um bom começo. Os encontros sobre novas tendências na área mobilizaram em 1999 e 2000 mais de 150 pesquisadores - VIII Colóquio Internacional sobre Poder e Organizações Locais, realizado na UFBA, e o $1^{\circ}$ Encontro de Estudos Organizacionais, realizado pela Associação Nacional dos Programas de Pós-Graduação em Administração (ANPAD).

Na ANPAD, o tema organizações e gestão é um eixo transversal de todo o encontro, que há muito demanda outro recorte. Se contarmos apenas os trabalhos da própria área e conexas (como estratégia, recursos humanos e administração pública), podemos dizer que cerca de 100 trabalhos dos 500 submetidos representam boas contribuições.

Quinto, dispomos de informações abundantes, disponibilizadas nas formas tradicionais: cinco revistas de administração, maciça produção editorial de autores nacionais e traduções quase em tempo real; os bancos de dados digitais e uma comunicação muito mais intensa da comunidade de aprendizagem tupiniquim. A "comodificação" do conhecimento, analisada por Rodrigues (1999), disponibiliza grande diversidade de produtos como CD ROOM, websites, cursos eletrônicos, vídeos etc. que funcionam como recursos, mas tendem a substituir o professor.

Sexto, nos 500 anos do descobrimento, estamos também descobrindo o Brasil. Temas como identidades, culturas locais, poderes locais, organizações típicas do contexto brasileiro, bem como a replicação de estudos internacionais sobre interculturalidade, novas tecnologias, gênero, novas formas organizacionais, instituições e regulação, cognição e emoções no mundo do trabalho conferem um maior estatuto de brasilidade ao que fazemos.

Sétimo, há um movimento seguro no sentido da internacionalização dos programas brasileiros, determinados pelos efeitos da globalização e pela via de mão dupla dos interesses de escolas estrangeiras de se estabelecerem ou se relacionarem com o Brasil e o interesse dos estudantes e professores nesta relação.

Oitavo, a diversificação dos programas de pós-graduação (doutorado e mestrado acadêmicos x mestrados profissionalizantes e especialização), bem como a proliferação de formatos (cursos em tempo integral/parcial, de longa/curta duração, em escolas ou in company, presenciais e à distância) criaram uma formidável dinâmica, em que as escolas contracenam com o mercado com grande intensidade, provocando mudanças nas políticas de pesquisa e ensino.

Nono, a avaliação e a certificação foram impostas de fora para dentro e de dentro para fora. O sistema de avaliação nacional, conduzido com exclusividade pela CAPES até aqui, passa a conviver com outros sistemas, como a ISO 9000, 
diretamente importada do mundo empresarial ou pelas iniciativas de associações de escolas como a ANPAD, prestes a criar um sistema de acreditação próprio. No que diz respeito ao conhecimento produzido na área, a crítica é mais presente na década de 90 e tende a se acirrar (Machado-da-Silva et al., 1990; Vergara e Carvalho Jr., 1995; Bertero, et al., 1997).

Décimo e último ponto, a revolução no ensino chegou e agita as escolas brasileiras. São propostas de mudanças na graduação e pós-graduação como reflexo das novas relações da sociedade cada vez mais demandante por ensino, das políticas nacionais indutoras de transformações institucionais e das mudanças na cultura de trabalho das instituições.

O campo de organizações e gestão, os chamados Estudos Organizacionais, é o eixo principal dos cursos, incorporando e expressando tendências. Reconhecer a sua complexidade e discutir alternativas para ensinar e aprender a partir da natureza pluriparadigmática da área é o nosso desafio a seguir.

\section{Estudos Organizacionais: Sentidos, Significados e Comunidades de Aprendizagem}

\section{Um Campo Polissêmico e Híbrido}

A fartura de metáforas sobre o estado da arte dos estudos organizacionais é reveladora do teor polissêmico do debate.

Leito de procusto ou torre de marfim, consenso ortodoxo ou pluralismo radical, a matéria ou corpus de conhecimento é tratada diferentemente, segundo o ângulo de visão ou opção paradigmática; no entanto a maioria dos autores não trata da questão do conteúdo como matéria de ensino.

As críticas recíprocas e as diferentes visões, muito polarizadas, curiosamente têm um ponto de consenso: aludem a uma suposta disciplina que tem como objetos empíricos a organização e a gestão (Martinet, 1990; Clegg et al., 1996; Weick, 1997; Déry, 1998; Girin, 1999).

Em um contínuo, que vai do consenso ortodoxo estruturado em torno do funcionalismo e seus desdobramentos no gerencialismo contemporâneo e a deconstrução/reconstrução pós-moderna ou o ressurgimento do pensamento radical crítico (Aktouf, 1998; Dehler et al., 1999), a teoria não explora, em geral, a questão epistemológica das formas do conhecimento organizado com objetivos de ensino. 
Nos limites deste trabalho, interessa-nos o conhecimento organizado como matéria dos atos de aprender e ensinar. Ao questionar o que são os estudos organizacionais, Clegg (1998) reconhece "não ser uma tarefa fácil" e prefere conceituar a área como um conjunto de conversações dos estudiosos do tema organizações e gestão, "conversações progressivas, com vocabulários e gramáticas emergentes e com vários graus de descontinuidade". A descontinuidade é acompanhada, a nosso juízo, de fragmentação e recomposição de temas, sentidos e significados. É obviamente distinto o significado de organizações para Champy (1996) e para autores mais representativos de correntes de pensamento mais ajustadas em Ciências Sociais, como Chanlat (1996), Linstead (1996), Enriquez (1997), Reed (1999) e outros.

Há divergências quase incontornáveis dentro das mesmas correntes, como a polêmica entre Gibson Burrell e Gareth Morgan ou entre linhas de trabalhos contemporâneos, mas com focos diversos, como revela o embate entre Henry Mintzberg e Marta Calás, sobre a descontração crítica feita pela segunda aos estudos de gerência realizados pelo primeiro. A diversidade de abordagens, correntes e vieses remete à diversidade dos paradigmas disciplinares que sustentam o campo.

Os estudos sobre organizações e gestão são uma confluência poliparadigmática e multirreferencial para a qual contribuem especialmente as disciplinas de Ciências Socias, Sociologia, Ciência Política, Antropologia, Psicologia, História e Economia. Outros campos disciplinares, com maior ou menor densidade científica, são invocados para o estudo das organizações contemporâneas, de forma substantiva (como a Física Quântica) ou adjetiva (como a Química e a Matemática); mas é notadamente nas Ciências Sociais que a ancoragem é mais constante e sólida, como constata Chanlat (1998).

Economia, Sociologia e Ciência Política são campos disciplinares que contribuem historicamente para os estudos organizacionais. A Economia foi a disciplina mais determinante no final do século XIX e em grande parte do século XX, sendo substituída em parte pela Sociologia ou Psicologia, a partir dos anos 30 até a implosão dos anos 80, quando a Antropologia e a Ciência Política se afirmaram pelas contribuições nos estudos de cultura organizacional ou nos estudos sobre o poder e as instituições.

A Psicologia retorna com ímpeto ao focalizar a cognição (Bastos, 1999) e emoções no mundo do trabalho (Dejours, Enriquez, Amado).

A partir dos anos 80 , as rupturas paradigmáticas têm três direções: a afirmação de campos de saber interdisciplinares, como a Psicossociologia; o uso de abordagens interdisciplinares para temas complexos como cognição, cultura, gêne- 
ro, estratégia, tecnologia e outros; e a tentativa de encontrar uma nova disciplina de síntese, como foi a Economia no século XX, até a Sociologia e a Psicologia entrarem nas agendas acadêmicas.

Nos anos 80 e 90, a disciplina de síntese proposta é a Antropologia (Chanlat, 1998). Na defesa da Antropologia como manto protetor, capaz de dar conta da análise de fenômenos organizacionais complexos, é evidente o desejo de encontrar a síntese de conhecimentos fundamentais sobre o homem em ação e sobre as organizações por ele criadas.

Invocando Marcel Mauss, Fernand Braudel, Georges Gusdorf e Edgar Morin, Chanlat (1998) apela à atribuição de uma Antropologia não disciplinar. "Tal Antropologia repensa, de uma parte, em certa abertura disciplinar e, de outra, sobre o retorno às dimensões centrais freqüentemente esquecidas no mundo da gestão" (Chanlat, 1998).

Seria uma disciplina, por mais flexível que fosse em suas fronteiras ou mais integradora de outros campos do saber, capaz de articular os diversos corredores do conhecimento em Ciências Sociais? Uma única disciplina, por mais compreensiva que seja, terá densidade e amplitude suficientes para ser um megaparadigma?

A diversidade de paradigmas é uma discussão recorrente e observamos muito mais a convivência, superposição e conflitos paradigmáticos do que a grande síntese sugerida pela incomensurabilidade. Ao lidarmos com diversidades, fazemos escolhas. Temos tanto a diversidade diacrônica (várias escolas de pensamento que se justapõem, sucedem ou superpõem) quanto a sincronização de temas e tópicos.

Como exemplo, Hatch (1997) elegeu estratégia, ambiente, tecnologia, estruturas social e física e cultura como conceitos-chaves no estudo de organizações. Como temas transversais relevantes, poder, decisão, controle, mudança e aprendizagem. É uma escolha sincrônica, no tempo em que a autora divide, diacronicamente, em eras ou fases marcadas por objetos empíricos, métodos e resultados.

Histórias, metáforas e perspectivas são os recursos de construção e difusão na pesquisa e no ensino, como matéria entendida como recorte de conhecimentos selecionado com objetivos de ensinar e aprender. Como categorizar os estudos organizacionais enquanto matéria de ensino? Pode ser uma disciplina na concepção ortodoxa?

Um conjunto expressivo de pensadores representados por Reed discute "a disciplina como um conglomerado paradigmático" e, em nossa visão, deixamos de ter uma disciplina (por maiores pretensões que tenham os seus adeptos) e passa- 
mos a ter formas interdisciplinares. Como contexto institucionalizado das disciplinas, o currículo é uma estrutura poderosa e inercial, caixa de ressonância da sociedade e da cultura onde está inserido.

\section{Estruturas Curriculares em Mutação}

Todo curso tem uma estrutura conceptual e metodológica e assume um formato curricular. O que chamamos currículo é a estrutura aparente de uma trama intrincada de fatos, conceitos, princípios e generalizações, que são a matéria do ensino e a dimensão substantiva do currículo.

A dimensão sintática da matéria do ensino (ou as estratégias de investigação e difusão) integra o currículo e, quanto mais aplicada for a área, mais sensível será, suscitando, como ocorre nos estudos organizacionais, as tensões entre a teoria e a prática. A importância do debate teoria/prática tem que ver diretamente com a natureza dos estudos organizacionais como área de conhecimento e matéria de ensino.

Como bonecas russas, metáfora usada por Dèry (1999), a construção do conhecimento, a produção derivada e sua utilização social são processos organicamente articulados e interdependentes.

Os meios de difusão do conhecimento tradicionais ou mais recentes, como a massificação digital, são semelhantes a um origami japonês: sobras da mesma figura no espaço. O currículo tem uma estrutura profunda e uma estrutura de superfície. Nada tão reflexivo e representacional quanto um currículo.

Afinal, é um mapa e uma árvore do conhecimento, com forma difusa e muitos fluxos de ação. Não é apenas proposta de ensino, expressa em caminhos críticos e ementas. Entende-se por currículo de um curso de formação profissional o conjunto de matérias, modos e meios de ensino e aprendizagem, decorrentes do contexto cultural e da natureza das áreas de conhecimento envolvidas, que assumem a configuração de disciplinas ou interdisciplinas a serem desenvolvidas cooperativamente por professores e alunos, visando ao desenvolvimento de competências socialmente desejáveis (Fischer, 1991)

Se o conhecimento se transforma e se discutem os megaparadigmas (Doll, 1997), a evolução do formalismo rígido para modelos consistentes e flexíveis de currículo, como interpretar o que é socialmente desejável?

Um dos campos mais férteis da Educação, os estudos sobre currículo estão revigorados, no momento em que a universidade como organização está em profunda transformação (Doll, 1997; Bayer e Apple, 1998; Sacristan, 1999). 
Como as instituições vão interpretar o que é socialmente desejável? A "anarquia organizada" de Cyert e March não tem mais a mesma autonomia de antes. É cada vez mais regulada (Musselini,1997). A competição veio para ficar e as organizações universitárias respondem aos imperativos da qualidade tanto quanto qualquer outra organização.

Manter os valores acadêmicos ou redefini-los dentro de um cenário de disputa de mercado, internacionalização de ensino, revolução digital e individualismo exarcebado, nada disso é trivial enquanto tarefa. Como o contexto vai espelhar-se no currículo?

A resposta mais simples é como sempre foi. A história dos estudos curriculares deste século fez um nexo muito forte com o gerenciamento científico. Franklin Bobbit e Elwood Culbberley, nos anos 10 e 20, incorporaram as idéias de como o currículo deveria ser planejado e organizado segundo os princípios tayloristas. A racionalidade técnica e a eficientização presidem a construção de currículos como linhas de montagem, cujas unidades operativas são as disciplinas, "o que veio aumentar a produtividade nas décadas de 20, 30 e 40" (Doll, 1997).

O fluxograma curricular funcionaria como uma seqüência, com pré-requisitos formais e rígidos. As disciplinas articulavam-se verticalmente. No caso brasileiro, os currículos adotados no país nos anos 50 e usados inercialmente até hoje, foram exportados pelas duas escolas americanas que mais influenciaram o ensino brasileiro (Michigan State e Southern California), adotados em toda a lógica funcionalista e reproduzidos em todo o país.

As escolas foram divididas em cursos de administração pública e de empresas e as áreas funcionais recursos humanos, produção, marketing e finanças estavam presentes em todos os cursos.

O campo de organizações e gestão foi fragmentado em disciplinas generalistas (como a então chamada Teoria Geral da Administração) ou em disciplinas focalizadas em temas de forte viés comportamentalista (como chefia e liderança, por exemplo). As disciplinas existentes nas estruturas de ensino de pós-graduação e graduação no Brasil são, em sua maioria, herança do consenso ortodoxo ou filhas legítimas do modernismo do século passado.

Currículos verticalizados, com linhas curriculares estanques e seqüência de pré-requisitos, estruturas piramidais rígidas na forma e no fundo: se for feita uma leitura da estrutura de superfície, esta é a realidade do ensino de $3^{\circ}$ grau. $\mathrm{O}$ modelo da graduação reproduz-se na pós-graduação até os anos 80, quando os cursos criados nesta época (Universidade Federal de Minas Gerais - UFMG, Universidade Federal da Bahia - UFBA, Universidade Federal de Santa Catarina - UFSC) tentaram inovar, trazendo organizações e gestão para o centro do curso. 
A desconstrução chegou nos anos 80 e 90 pela incorporação das críticas radicais de Habermas, Foucault, Enriquez, Aktouf e outros. A contribuição da escola de Frankfurt, da psicossociologia francesa, da epistemologia aplicada à gestão (Martinet e Audet), dos estudos britânicos sobre trabalho e organizações (Wood, Silverman) e toda a fragmentação das Ciências Sociais, com a emergência de temas e abordagens interdisciplinares, vão superpondo-se às propostas paradigmáticas tradicionais e abrindo rachas nos currículos e programas.

Não foram opções consensuais. Os novos temas foram agregando-se de forma desordenada, como vinhos velhos em garrafas novas, como intrusões mais ou menos conflitivas trazidas por novos professores ou como apostos sem reconhecimento maior da comunidade dos pares. Isto porque, no Brasil, os confrontos em departamentos e cursos são resolvidos por justaposição. Criam-se mais disciplinas e os interesses são relativamente acomodados e a inércia prevalece. Em qualquer caso, os currículos, especialmente na graduação, onde os problemas de ajuste são mais difíceis do que na pós-graduação, são uma torre de babel, na qual as disciplinas não se articulam bem, nem verticalmente nem horizontalmente.

No início do ano 2000, as diretrizes curriculares do MEC subvertem a ordem, na proposta de um currículo orbitalizado. As diretrizes curriculares para a reorganização dos cursos de graduação adotam princípios de identidade dos cursos, autonomia, interdisciplinariedade, contextualização e flexibilidade, propondo currículos orbitalizados em substituição aos antigos modelos piramidais.

Na pós-graduação, sem indução externa explícita, os cursos vão mudando, influenciados que são pelas mudanças em escolas de referência internacional, pelas demandas de mercado e pelas transformações das organizações e da gestão, reflexivamente ressignificadas.

É interessante observar que as tradicionais separações entre administração pública e de empresas, que foram a clivagem fundamental no nosso pretérito imperfeito, não têm mais sentido no presente composto. Um gestor pode, sem sair da mesma organização, passar da condição de funcionário público para empregado, como as privatizações mostraram.

As empresas que fazem projetos de cidadania ou solidariedade empresarial recrutam executivos no setor público ou deslocam pessoas de outras áreas da empresa. As ONGs, cada vez mais profissionais, são dirigidas por egressos do setor privado.

Está bem mais difícil pesquisar e ensinar do que há 20 ou 30 anos. Como lembra Rodrigues (2000), "os estudiosos das décadas de 60, 70 e 80 tinham uma postura bem confortável, uma vez que o sujeito de análise lhes parecia menos complexo, sendo ao mesmo tempo mais delimitado". 
Hoje, as organizações dificilmente podem ser vistas isoladamente. Na verdade, vivemos em interorganizações reais e virtuais e a gestão é coletivizada na perspectiva dos estudos sobre governança, não apenas nas corporações mas em todas as instâncias da sociedade.

E aí, feito um sumário diagnóstico, pergunta-se: pode-se considerar hoje o conhecimento em organizações e gestão como disciplinar? Estamos, de fato, tratando de uma disciplina com estrutura conceptual bem definida ou, de fato, de um campo com características interdisciplinares?

Para iniciar esta discussão, vamos recorrer às fontes que refletem sobre epistemologia e ensino integrado, que é do que estamos tratando relativamente aos estudos organizacionais. Em 1970, o debate sobre a integração do conhecimento acirra-se e a interdisciplinaridade retorna à agenda acadêmica, trazida pelo estruturalismo piagetiano, pelo marxismo de Vigotsky, pelas críticas à fragmentação do conhecimento nas instituições de ensino feitas por Dewey e pelas contribuições de Whitehead e Bruner sobre as estruturas de cognição.

Da epistemologia positivista avança-se para um conceito de epistemologia hermenêutica. "Tal epistemologia não vai lidar somente com a verdade, mas também com a diversão, com o paradoxo, com a complexidade e a indeterminância, para citar apenas alguns aspectos daquilo que se torna significativo no mundo em que vivemos" (Doll, 1997).

Atualmente, no início do novo milênio, estamos no meio da formação de um novo paradigma, ou de um megaparadigma, apoiado nos estudos sobre complexidade e ordem caótica?

Auto-organização, caos e estruturas dissipativas têm sido usados para o bem e para o mal, como conceitos no campo organizacional. Estão presentes similarmente nos estudos curriculares (Doll, 1997; Apple, 1999; Santomé, 1999).

Não é nosso objetivo discutir o seu emprego, mas chamar a atenção para o quanto nos aproximamos dos novos paradigmas de estudos educacionais, nos quais ganham destaque o desenho curricular e a necessária integração entre conhecimentos teóricos e entre teoria e prática, polêmica recorrente entre os que pensam sobre a organização e os que nela atuam.

As unidades operativas dos currículos e as tradicionais disciplinas perderão espaço para arranjos curriculares mais complexos. Se as disciplinas podem ser justapostas e funcionarem por coordenação, a interdisciplinaridade supõe temas transversais e, no mínimo, interesses comuns de várias disciplinas.

Neste ponto, é interessante saber o que pensam os professores, de quem depende a mudança e como eles se estão organizando para enfrentá-la. 


\section{As Vozes dos Professores: do Discurso Solitário à Comunidade de Aprendizagem}

Em pesquisa em curso sobre os estudos organizacionais no Brasil e no exterior realizada com professores e pesquisadores que se dedicam ao tema e são reconhecidos por seus pares, foi solicitado o depoimento sobre objetivos de formação, sobre o que é relevante ensinar sobre as organizações e como deve ser este ensino. Até o momento, coletamos 56 depoimentos.

$\mathrm{Na}$ opinião dos professores, os objetivos gerais da formação, aplicáveis ao estudo de organizações e da gerência, devem orientar-se para o desenvolvimento das capacidades de aprender com a transição. A multiqualificação, determinada pelo reconhecimento das inteligências múltiplas, de processos mentais e de estruturas de cognição/afetividade implica conhecer os fundamentos da sociedade e reconhecer os sistemas complexos; utilizar lógicas lineares e não lineares associadas ao caos e à complexidade; pensar criticamente sobre a mudança e liderar processos.

Isto se aplica diretamente às organizações complexas com que estamos lidando hoje, híbridas e multiculturais. É consenso no grupo de entrevistados que as organizações atingiram importância e papel sem precedentes na história brasileira. O grande desafio é a institucionalização de novas regras de jogo e práticas sociais. Como as organizações são mediadoras da ação humana, são também não apenas objetos empíricos de pesquisa, mas espaços de formação.

Inquiridos sobre o ensino de organizações, os professores destacaram os pontos abaixo listados sobre o que é relevante ensinar.

- Apresentação dos estudos organizacionais como uma construção coletiva, confluência de múltiplos paradigmas evolutivos em sua natureza. Deve ser feita distinção clara das contribuições das diferentes comunidades de discurso internacionais e nacionais presentes no campo, pois as teorias devem ser apropriadas ao contexto em que foram criadas, isto é, que objetivos se propunham e que problemas pretendiam resolver. A aplicabilidade destas teorias ou o poder de explicação da realidade brasileira é uma discussão fundamental.

- A importância das organizações no mundo contemporâneo como unidade associativa que interliga diversidades como grupos, cidades, regiões e países, em formas organizacionais crescentemente mais complexas. Na construção das novas institucionalidades locais e globais, a contribuição organizacional é decisiva. 
- A história das organizações brasileiras, com destaque para as contribuições teóricas e empíricas, isto é, tanto o resgate de pensadores, quanto as experiências de construção organizacional nos setores público, empresarial e no terceiro setor.

- Seleção de tópicos de interesse, presentes nos estudos organizacionais, como design organizacional, estratégia (múltiplos sentidos e vertentes), organização do trabalho relacionada às questões de emprego e tecnologia, o papel do indivíduo na dinâmica organizacional, especialmente as questões referentes aos conflitos do trabalho e às dimensões culturais das organizações brasileiras.

Sobre o como ensinar, ou sobre a questão dos métodos, dizem os professores:

- A construção do conhecimento no campo adotará uma perspectiva históricodiacrônica, possibilitando a reconstrução crítica pelo aluno das trajetórias teóricas.

- A exposição do aluno a teorias deve ser seguida ou medida por métodos interativos e/ou representativos da realidade. O estudo metódico de casos, resultante de pesquisas da realidade local/nacional, é ainda um vigoroso recurso, desde que fortemente articulado às teorias em estudo.

- Abordagens dedutivas e indutivas serão intercaladas e articuladas, possibilitando a compreensão do todo e dando significado às partes.

- A pesquisa-ação, que pode estar integrada à consultoria institucional, é um recurso de imersão a ser utilizado, aproximando o aluno das organizações reais.

- Os métodos tradicionais de estudo apoiados em publicações convencionais e modos de ensino centrados na figura do professor, como a exposição, dividem espaços com recursos informáticos e ensino à distância. A alternância de métodos é uma diretriz importante.

Aulas expositivas e seminários são revalorizados, especialmente como recursos de organização do aluno em face da massa de informações disponíveis atualmente, por meios informatizados ou não.

Os últimos vinte e cinco anos possibilitaram o surgimento e maturação de uma comunidade de estudos organizacionais no Brasil, que já discute identidade nacional e sua própria identidade. Sem xenofobia nem submissão, a comunidade brasileira passa a enfrentar os seus próprios problemas, pontos de tensão e convergência. 


\section{À Guisa de Conclusão: Seis Princípios para o Decênio 2000/2010}

Este decênio é um referencial simbólico para o século. Em dez anos, duas ou três gerações de professores estarão em atividade. O quarto de século precedente foi de institucionalização de uma área jovem. Formação de quadros, iniciação de pesquisa e criação ou consolidação de laços nacionais e internacionais foram medidas pioneiras.

A produção do conhecimento pela pesquisa, a difusão por meio de veículos tradicionais e alternativos e a difusão direta pela formação de profissionais, docentes e pesquisadores ocorrem em vários níveis, da iniciação à qualificação avançada. As mudanças curriculares no ensino da graduação e pós-graduação são reflexos e movimentos autônomos.

No momento, o ensino volta com toda a força ao centro das atenções. Só que não estamos mais reproduzindo modelos. O que se observa nas escolas brasileiras é um aglomerado de posturas e tendências, que vão do conservadorismo de conteúdos e modos tradicionais de ensinar à reedição do radicalismo crítico, mais ou menos articuladas com a tecnificação do ensino digital e a nova estética, ou o uso de recursos estéticos como inspiradores da aprendizagem.

Voltando aos princípios de Calvino (1991), é um grande desafio ensinar e aprender sobre organizações e gestão nas instituições brasileiras dispersas em um país com dimensões continentais e tantas diferenças.

Para enfrentar a massificação, aposta-se na consistência. Para vencer a inércia ortodoxa, aposta-se na agilidade das mudanças. Precisão ou rigor no tratamento do campo, simplicidade nas propostas curriculares, fazendo menos e melhor, revertendo a fragmentação.

Para finalizar, sublinhe-se a multiplicidade por meio de parcerias e alianças no país e no exterior e o investimento sistemático na criação de uma comunidade dos que aprendem ao ensinar e dos que ensinam ao aprender ${ }^{(1)}$.

\section{Nota}

${ }^{1}$ Colaborou neste trabalho o aluno Mário Vinícius de Mattos, bolsista de iniciação científica do CNPq. 


\section{ReferênCIAs Biblográficas}

AKTOUF, O.

Administración y pedadogía. Bogotá: EAFIT, 1998.

AMADO, G.;

DEUMIE, C.

Pratiques magiques et regressives dans la gestion des ressources humaines. Revue Française de Gestion des Ressources Humaines, 1990.

BALME, R. et al.

Les nouvelles politiques locales. Paris: Presses de Sciences, 1999.

BASTOS, A. V.

Organização e cognição: explorando um olhar da psicologia sobre os processos organizacionais. 1999. trabalho não publicado.

BAYER, L.;

APPLE, N.

The curriculum: problems, politics and possibilities. New York: State University, 1998.

BERTERO, C. et al.

Produção científica em administração de empresas: provocações, insinuações e contribuições para um debate local. In: XXI ENCONTRO ANUAL DA
ANPAD (1997: Angra dos Reis). Anais Eletrônicos... Angra dos Reis: ANPAD, 1997.

CALVINO, I.

Seis propostas para o próximo milênio. Rio de Janeiro: Civilização Brasileira, 1991.

CHAMPY, J.

Reengenharia da gerência. Rio de Janeiro: Campus, 1996.

CHANLAT, J. F.

$O$ indivíduo nas organizações. São Paulo: Atlas, 1996.

Sciences sociales et management. Paris: ESKA, 1999.

CLEGG, S. R.;

HARDY, C.;

NORD, W. R. (Eds.).

Handbook of organization studies. London: Sage Publications, 1996.

DEHLER, G. et al.

Critical pedagogy in 'new paradigms'. Trabalho apresentado no seminário 'Praising Complicated Understanding in Management Learning', Manchester, 1999. 
DÈRY, R.

Princípios e controvérsias epistemológicas no campo das ciências da gestão. Revista Canadense de Administração, v. 9, n.1, out./nov. 1999.

DOLL, W.

A post modern perspectives on curriculum. Nova York: Teachers College, 1997.

ENRIQUEZ, E.

Les jeux du pouvoir et du désir dans l'entreprise. Paris: Desclée de Brower, 1997.

\section{FISCHER, T.}

Administração pública como área de conhecimento e ensino: a trajetória brasileira. Revista de Administração de Empresas, v. 24, n. 4, out./dez. 1984.

Ensino de administração no Brasil, os ideais do desenvolvimento e as dimensões de racionalidade. São Paulo, 1984. Tese (Doutorado) - Universidade de São Paulo.

Currículos em mudança. Rio de Janeiro: UNESCO, 1991.

\section{GIRIN, J.}

Agências e construção do conhecimento científico em organizações. In: VIII COLÓQUIO
INTERNACIONAL SOBRE O PODER LOCAL (1999: Salvador). Anais Eletrônicos... Salvador: 1999.

HATCH, M. J.

Organization theory. New York: Oxford University Press, 1997.

JOUVE, B.

Qui gouvernent les régions d'Europe? Paris: L'Armattan, 1996.

LE GALLÈS, P.;

BAGNASCO, A.

Villes en Europe. Paris: La Découverte, 1997.

LINSTEAD, S.

Understanding management. London: Sage Publications, 1996.

MACHADO-DA-SILVA, C. L.;

CUNHA, V. C.;

AMBONI, N.

Organizações: o estado da arte da produção acadêmica no Brasil. In: XIV ENCONTRO ANUAL DA ANPAD (1990: Florianópolis). Anais... Florianópolis: ANPAD, 1990. v. 6. p. 11-28.

MARTINET, A.

Epistémologies et sciences de gestion. Paris: Economica, 1990. 
MOURA, S. A

Gestão do desenvolvimento local: estratégias e possibilidades de financiamento. In: XXII ENCONTRO ANUAL DA ANPAD (1998: Foz do Iguaçu). Anais... Foz do Iguaçu: ANPAD, 1998.

MUSSELINI, C.

Le gouvernement des universités. Paris: L'Armattan, 1997.

REED, $M$.

Teorização organizacional: um campo teoricamente contestado. In: CLEGG, S. R.; HARDY, C.; NORD, W. R. (Eds.). Handbook de estudos organizacionais. São Paulo: Atlas, 1999. v. 1.

RODRIGUES, S. B.

From factories to shops: deconstruction of scientific knowledge without a client. In: 15TH EUROPEAN GROUP OF ORGANIZATION STUDIES COLLOQUIUM (1999: Warwick). Proceedings... Warwick: 1999.
Representações: a importância do sujeito na teoria organizacional. In: CLEGG, S. R.; HARDY, C.; NORD, W. R. (Eds.). Handbook de estudos organizacionais. São Paulo: Atlas, 2000. v. 2.

SACRISTAN, J.

Globalización e interdisciplinaridad - el curriculum integrado. Madri: Morate, 1999.

VELTZ, P.

Mondialisation, villes et territoires - Paris. Paris: Economie et Libertè, 1996.

VERGARA, S.;

CARVALHO JR., D.

Nacionalidade dos autores referenciados na literatura brasileira sobre organizações. Revista Brasileira de Administração Contemporânea, v. 1, n. 6, out./nov. 1995.

WEICK, K.

The teaching experience as learning in public. In: ANDRÉ, R.; FROST, P. Researchers hooked on teaching. London: Sage Publications, 1997. 